\title{
TERAPIA SISTÉMICA: UNA REFORMULACIÓN DE SUS PRINCIPIOS BÁSICOS EN TÉRMINOS DE JUEGOS DE LENGUAJE*
}

\author{
SYSTEMIC THERAPY: A REFORMULATION OF \\ ITS BASIC PRINCIPLES IN TERMS OF \\ LANGUAGE-GAMES
}

\author{
JOSÉ MARÍA ARISO \\ Universidad Internacional de La Rioja
}

Resumen: Aunque Steve de Shazer y otros autores han usado el concepto wittgensteiniano de «juego de lenguaje» para entender el modo en que la realidad es percibida y conceptualizada por el cliente, es necesaria una reformulación de los principios básicos de la terapia sistémica en términos de juegos de lenguaje. En este artículo llevaré a cabo dicha reformulación al señalar algunos paralelismos entre la terapia sistémica y la filosofía tardía de Wittgenstein en relación con su noción de «enfermedad»; la prioridad concedida a la disolución sobre la solución tanto de sistemas-problema como de problemas filosóficos; la importancia de ofrecer una perspectiva más amplia de los correspondientes problemas, y sobre todo, la dificultad de afrontar las resistencias que aparecerán a medida que avance el proceso de disolución. Además, estos paralelismos arrojarán luz también sobre algunos aspectos tan importantes de la filosofía tardía de Wittgenstein como su convicción de que la filosofía deja todo como está.

PALABRAS CLAVE: terapia sistémica, juego de lenguaje, sistema-problema, problema filosófico, disolución, enfermedad.

ABSTRACT: Though Steve de Shazer and other authors have used the Wittgensteinian concept of «language-game» to understand the way reality is perceived and conceptualized by the client, a reformulation of the basic principles of systemic therapy in

\footnotetext{
${ }^{*}$ Este artículo ha sido realizado dentro del marco del proyecto de investigación «Normatividad y Praxis: El debate actual después de Wittgenstein» (FFI2010-15975).
} 
terms of language-games is needed. In this paper, I will carry out this reformulation by pointing out some parallelisms between systemic therapy and Wittgenstein's later philosophy about his notion of «illness» as well as the priority of dissolution over solution for both problem-systems and philosophical problems, the importance of providing a broader perspective of the corresponding problems, and above all, the difficulty of facing up to the resistances that will arise as the process of dissolution advances. Moreover, these parallelisms will also shed light on some important aspects of Wittgenstein's late philosophy such as his conviction that philosophy leaves everything as it is.

KEYWORDS: systemic therapy, language-game, problem-system, philosophical problem, dissolution, illness.

\section{Introducción}

A lo largo de las últimas décadas, ninguna otra modalidad psicoterapéutica ha experimentado una evolución tan significativa en su ámbito de aplicación y muy especialmente en su fundamentación teórica como la terapia sistémica. Pues si bien este tipo de terapia hunde sus raíces teóricas en la Teoría General de Sistemas ${ }^{1}$, la Cibernética $^{2}$ y la Teoría de la Comunicación ${ }^{3}$, con el paso de los años ha ido centrando progresivamente su atención en el lenguaje: este cambio de perspectiva, originado inicialmente por la influencia de la cibernética de segundo orden y del pensamiento constructivista, generó diversas ramificaciones dentro del enfoque sistémico. Así, White y Epston se centraron en las reflexiones de Foucault sobre la naturaleza del discurso dominante ${ }^{4}$; Anderson y Goolishian se inspiraron en la narrativa y en el construccionismo social ${ }^{5}$; y algunos autores como Boscolo et al. ${ }^{6}$

\footnotetext{
${ }^{1}$ Cfr. von Bertalanffy, L. (1954): General systems theory, New York, George Brazillier.

${ }^{2}$ Cfr. Wiener, N. (1948): Cybernetics, New York, Wiley.

${ }^{3}$ Cfr. Watzlawick, P., Beavin, J. \& Jackson, D. (1967): Pragmatics of human communication, New York, Norton.

${ }^{4}$ White, M. \& Epston, D. (1989): Literate Means to Therapeutic Ends, Adelaida, Dulwich Centre Publications.

${ }^{5}$ Anderson, H. \& Goolishian, H. (1988): «Human systems as linguistic systems: evolving ideas for the implications in theory and practice», Family Process, XXVII, pp. 371-393; Anderson, H. \& Goolishian, H. (1992): «The client is the expert: a not-knowing approach to therapy», en McNamee, S. \& Gergen, K. J. (eds.), Therapy as Social Construction, London, Sage, pp. 25-39.

${ }^{6}$ Boscolo, L., Bertrando, P., Fiocco, P. M., Palvarini, R. M. y Pereira, J. (1991): «Linguaggio e cambiamento. L'uso di parole chiave in terapia», Terapia Familiare, XXXVII, pp. 41-53.
} 
y sobre todo De Shazer ${ }^{7}$ concedieron una gran importancia a la noción wittgensteiniana de «juego de lenguaje». El interés suscitado en torno a este concepto por parte de los citados autores se debe a su firme convicción en la necesidad de trazar un límite metodológico en torno a la situación terapéutica: partiendo de que el contexto social en el que los hombres desarrollan sus vidas viene dado por el consenso en su uso del lenguaje, se presupone que el mejor modo de comprender la construcción de la realidad que el cliente manifiesta en la consulta consiste en atender cuidadosamente a su uso del lenguaje y, por extensión, a la manera en que el cliente percibe y conceptualiza la realidad.

En el presente artículo pretendo profundizar en el análisis de la relación entre la terapia sistémica y el concepto wittgensteiniano de «juego de lenguaje» llamando la atención sobre múltiples paralelismos existentes entre el enfoque sistémico y la filosofía tardía de Wittgenstein. A mi modo de ver, hubiera sido mucho más fructífero que los terapeutas sistémicos investigaran la construcción de la realidad de sus clientes tomando como referencia no la noción de «juego de lenguaje», sino otra que Wittgenstein desarrolla en relación con su estudio de las certezas y su crítica al intento mooreano de refutación del escepticismo respecto a la existencia de los objetos físicos: me refiero a la noción de «imagen del mundo» (Weltbild $)^{8}$. Pero no será en este trabajo donde explique la utilidad de la expresión «imagen del mundo» para el propósito citado. Lejos de tal cosa, en el artículo que aquí presento comenzaré ofreciendo una breve introducción a las características fundamentales de la terapia sistémica y a algunos aspectos básicos de la obra tardía de Wittgenstein, dentro de la cual surge y se desarrolla la noción de «juego de lenguaje», para mostrar a continuación cómo este concepto puede ser usado como una herramienta ilustrativa de la dinámica de equilibrios y desequilibrios sistémicos en torno a la cual gira la terapia sistémica. Ahora bien, con el fin de cumplir con mi objetivo de profundizar en el análisis de la relación entre la terapia sistémica y el concepto de «juego de lenguaje», señalaré también cómo los avances y aportaciones de la terapia sistémica nos ayudan a

\footnotetext{
${ }^{7}$ De Shazer, S. (1985): Keys to Solution in Brief Therapy, New York, Norton; De Shazer, S. (1988): Clues. Investigating Solutions in Brief Therapy, New York, Norton; De Shazer, S. (1991): Putting Differences to Work, New York, Norton; De Shazer, S. (1994): Words Were Originially Magic, New York, Norton.

${ }^{8}$ Cfr. Wittgenstein, L. (1997a): Sobre la certeza, Barcelona, Gedisa, \$S 93-97, 162, 167, 233, 262. [En lo sucesivo se citará con las siglas «SC»].
} 
tener una visión más clara de aspectos tan importantes de la obra tardía de Wittgenstein como la conocida afirmación del filósofo vienés según la cual la filosofía «[d]eja todo como está»?.

\section{Principios básicos de la terapia sistémica}

Hasta hace sólo unas pocas décadas, las principales corrientes psicoterapéuticas se habían caracterizado por considerar los trastornos psicológicos desde una óptica similar a la perspectiva desde la que la epistemología newtoniana abordó los problemas de la mecánica, es decir, como una teoría referente a los movimientos de objetos inanimados, pasivos e inertes. Esta concepción del ser humano aquejado de problemas psicológicos se consolidó aún más si cabe al calificarlo como «enfermo» y especialmente al asignarle diagnósticos clínicos. Una vez que el sujeto ha sido diagnosticado, la responsabilidad de la cura parece recaer exclusivamente en el especialista, en el supuesto conocedor del funcionamiento de la mente enferma y del modo de curarla. A pesar de que el diagnóstico recibido puede tranquilizar al paciente porque da por hecho que el especialista ya sabe qué le pasa, lo cierto es que tanto el diagnóstico como el tratamiento del sujeto diagnosticado se basan en una concepción implícita de la normalidad a la que debe ser reintegrado el paciente. El enfermo es considerado como tal porque se ha alejado en una dirección u otra del canon de normalidad imperante en el contexto sociocultural de turno.

Frente a este reduccionismo que parece tomar al «enfermo» como un mecanismo más o menos predecible por concentrarse no en su inaprehensible dinámica sino en el diagnóstico formulado o la imagen estereotipada que el especialista se forma del paciente como un caso de tal o cual tipo, el enfoque sistémico no se centra en el trastorno de un individuo concreto sino en las relaciones que se establecen en un sistema en el que cada variación de uno de sus miembros provoca una variación en el resto de los elementos: dicho de otra manera, el enfoque sistémico presupone que toda conducta o manifestación verbal de un miembro del sistema repercute de un modo u otro en los demás miembros, por lo que hasta cierto punto la conducta de un miembro se puede entender tam-

\footnotetext{
${ }^{9}$ Wittgenstein, L. (1988): Investigaciones filosóficas, Barcelona, Crítica, \124. [En lo sucesivo se citará con las siglas «IF»].
} 
bién como el resultado de su interacción con la conducta del resto de miembros. Desde este punto de vista, el sistema aparece en constante cambio y evolución, no como un modelo estático. Sin embargo, dentro de cada sistema se adivinan unas pautas de relación características entre sus miembros: por citar sólo algunos ejemplos, un miembro puede adoptar habitualmente el papel de agresor mientras que otro acepta el papel de víctima, un sujeto puede mostrar reiteradamente una actitud hipocondríaca que provoca que los demás miembros del sistema estén pendientes de él, etc. Ahora bien, desde el punto de vista sistémico, en estos casos no hay trastornos sino determinadas secuencias comunicativas o formas de relacionarse cuya persistencia confiere equilibrio al sistema. De ahí que a la terapia sistémica no le interesen en absoluto las causas que en el pasado pudieran haber provocado una conducta que otros terapeutas considerarían «patológica»: lejos de tal cosa, lo importante desde el punto de vista sistémico es localizar cuál es la dinámica o pautas de relación que configuran el sistema que se quiere modificar. De hecho, el terapeuta sistémico intentará alterar el equilibrio de ese sistema facilitando así a sus miembros que comiencen a mostrar nuevas formas de relacionarse.

Al no partir de un canon de normalidad al que haya que reintegrar al cliente, para el terapeuta sistémico carece de sentido precisar si determinado sistema o pauta de relaciones es «anormal». A la hora de planificar el tratamiento, el terapeuta no debe pensar en reintegrar al cliente a una supuesta «normalidad», sino que debe partir del objetivo planteado por su cliente para definir conjuntamente con éste cuál es el encargo recibido: en otras palabras, el encargo plantea el objetivo propuesto por el cliente de modo que resulte realista y accesible dentro del contexto de la terapia. Cuando los clientes solicitan ayuda, el terapeuta debe precisar qué tipo de equilibrio desean alcanzar en sus relaciones; pues cuando el cliente plantea ante el terapeuta el problema que quiere tratar ya está presuponiendo, implícita o explícitamente, no sólo que hay determinados estados alternativos o modalidades relacionales que aceptaría como soluciones al problema propuesto, sino también que el cambio es posible ${ }^{10}$. Como bien apunta Ludewig, si el cliente no fuera capaz de concebir ninguna alternativa a su problema, éste no existiría dentro de su dominio cognitivo: así pues, la tarea del terapeuta va a consistir en guiar y estimular al cliente para que halle sus propios recur-

${ }^{10}$ Cfr. von Schlippe, A. \& Schweitzer, J. (2003): Manual de terapia y asesorías sistémicas, Barcelona, Herder, p. 116. 
sos y alternativas al problema de turno, ya que es el cliente y no el terapeuta quien mejor sabe qué estados y alternativas le sirven como solución a su problema ${ }^{11}$. Por tanto, será la opinión del cliente y no el avezado juicio del terapeuta lo que en último término establezca cuál ha sido el grado de éxito de la terapia.

Hace algunas décadas se aceptaba, en consonancia con la cibernética de primer orden, que el sistema determinaba el problema o síntoma a tratar; mas posteriormente, y siguiendo las directrices de la cibernética de segundo orden, se aceptó que es el sistema el que está determinado por el problema y no al contrario. En el ámbito de la terapia familiar, este cambio de perspectiva implica dejar de centrar la atención en la familia entendida como un grupo prefijado y generador de conflictos. Ya no son las personas las que tienen que cambiar, sino los sistemas de significado que se transmiten a través del lenguaje y que se van generando paulatinamente en torno a determinado problema. El sistema nocivo es el que Anderson, Goolishian y Winderman denominaron «sistema creado por el problema» (problem-determined system) ${ }^{12}$ : y es la pericia del especialista la que debe contribuir a que, en una fase inicial del tratamiento, dicho sistema se asiente y estabilice aún más si cabe dentro de un marco terapéutico generador de confianza. Esta confianza debe facilitar que el cliente se atreva a desestabilizar el «sistema creado por el problema» sustituyéndolo progresivamente por el sistema terapéutico y luego por un sistema alternativo que resulte incompatible con el problema. Así pues, el nuevo objeto de la teoría clínica será un proceso secuencial en el que se alternan distintos sistemas interrelacionales que se relevan sucesivamente. Dentro de esta dinámica, el sistema en el que se manifiesta el problema objeto del tratamiento es, como acabamos de ver, el «sistema creado por el problema», o según la denominación más abreviada de Ludewig, el «sistemaproblema». Este tipo de sistemas se caracterizan por su carácter recurrente y pueden originarse a partir de malentendidos y heridas emocionales provocadas voluntaria o involuntariamente: estas pautas de relación no se curan o solucionan sino que se disuelven cuando cada miembro del sistema es capaz de renunciar a seguir contribuyendo al mantenimiento del problema, aunque lo más frecuente es que estos sistemas-problema se desintegren por sí mismos ya sea porque la

\footnotetext{
${ }^{11}$ Cfr. Ludewig, K. (2010): Bases teóricas de la terapia sistémica, México, Herder, pp. 101-102.

${ }^{12}$ Anderson, H., Goolishian, H. \& Winderman, L. (1986): «Problem determined systems: towards transformation in family therapy», Journal of Strategic and Systemic Therapies, V, pp. 1-14.
} 
atención se desplaza a otro tema, el problema en cuestión se torna aburrido, se reinterpreta, o incluso se olvida ${ }^{13}$.

En este punto resulta conveniente distinguir también entre síntoma y problema: mientras que el primero se reduce a una conducta frecuente y disruptiva tras la cual se ocultan contenidos que un sujeto se abstiene de comunicar al resto de miembros del grupo, el segundo es más amplio y atañe al equilibrio en las relaciones de todo el sistema. El terapeuta sistémico debe aclarar cuál es el significado del síntoma para las familias o grupos que se ponen en tratamiento, pues dicha información le permitirá decidir su estrategia en pos del cambio buscado. A modo de ejemplo, el terapeuta trabajará sobre el miedo al cambio existente en la familia cuando se trate de un síntoma que desempeña una función protectora; tratará de distribuir el poder entre los distintos miembros del grupo cuando el síntoma sea un elemento de poder; alcanzará un acuerdo sobre la interpretación del fenómeno y enseñará a comunicar abiertamente los reproches o «deudas pendientes» cuando el síntoma constituya una forma de llamar de atención, etc. Con esta forma de proceder se presupone que el síntoma dejará de manifestarse cuando pierda el significado que le dio origen ${ }^{14}$, o lo que es lo mismo, cuando la intervención sistémica genere un cambio tal en el sistema de turno que el síntoma deje de ser coherente o inteligible dentro de ese contexto. En primera instancia podría parecer que la tarea del terapeuta debería limitarse a la eliminación del síntoma sin tener en cuenta el carácter global del problema; pero el modelo sistémico ha mostrado, como dicen Ceberio y Linares, que conformarse con el mero cambio sintomático puede resultar insuficiente si no se interviene sobre las relaciones del grupo: pues sólo así se podrá conferir estabilidad a los saludables cambios que se hayan producido en el sistema. Por consiguiente, el terapeuta sistémico debe atender tanto al síntoma como a las pautas de relación dentro de las cuales el síntoma, cuando existe, ocupa un primer plano ${ }^{15}$.

\footnotetext{
${ }^{13}$ Cfr. Ludewig (2010), pp. 88, 105-107.

${ }^{14}$ Cfr. Bermúdez, C. y Brik, E. (2010): Terapia familiar sistémica. Aspectos teóricos y aplicación práctica, Madrid, Síntesis, p. 180.

${ }^{15}$ Cfr. Ceberio, M. R. y Linares, J. L. (2005): Ser y hacer en terapia sistémica. La construcción del estilo terapéutico, Barcelona, Paidós, p. 84.
} 


\section{Wittgenstein y la filosofía como disolución de enredos gramaticales}

Podemos afirmar sin temor a equivocarnos que el concepto más importante dentro de la obra tardía de Wittgenstein es el de «juego de lenguaje» (Sprachspieð. Matizando ligeramente la definición de «juego de lenguaje» que el filósofo vienés ofreció en sus Investigaciones filosóficas, podemos decir que con esta expresión se refirió a cada una de las prácticas o contextos en que se insertan nuestros usos del lenguaje, si bien en dichas prácticas o contextos hay que incluir también todas aquellas actividades con que aparecen entrelazados los usos del lenguaje $\mathrm{e}^{16}$. Así, son ejemplos de juego de lenguaje « [d] ar órdenes y actuar siguiendo órdenes, (...) fabricar un objeto de acuerdo con una descripción, (...) actuar en teatro, cantar a coro, adivinar acertijos, (...) suplicar, agradecer, maldecir, saludar, rezar ${ }^{17}$ y todas y cada una de las prácticas lingüísticas —además de las actividades asociadas a ellas — propias de cada idioma. Ahora bien, cuando hablamos o participamos en un juego de lenguaje corremos riesgos como los de confundir las reglas de juegos de lenguaje distintos - lo cual sucede con especial frecuencia en el ámbito de la filosofía - o ser víctimas de la influencia que sobre nosotros ejercen las imágenes subyacentes a nuestro uso corriente del lenguaje. Wittgenstein tampoco ofrece una definición precisa de lo que entiende por «imagen» (Bild): simplemente dice que la imagen nos mantiene cautivos sin que podamos evitarla, «pues reside en nuestro lenguaje y éste parece repetírnosla inexorablemente» ${ }^{18}$. A tenor de lo dicho, puede parecer que Wittgenstein toma la imagen como una idea que, precisamente porque forma parte del lenguaje, es expresada explícitamente y con cierta frecuencia; sin embargo, Wittgenstein entiende la imagen como un presupuesto tan firmemente asentado en el uso corriente de nuestro lenguaje que no solemos reparar en él. En palabras de Wittgenstein: «No juzgamos imágenes, sino mediante imágenes. No son ellas lo que investigamos, sino, mediante ellas, algo diferente» ${ }^{19}$. Evidentemente, no todas las imágenes son dañinas o perniciosas para nuestro entendimiento. Sin ir más

\footnotetext{
${ }^{16}$ En las Investigaciones filosóficas Wittgenstein definió el «juego de lenguaje» como el «todo formado por el lenguaje y las acciones con las que está entretejido» (IF \ 7).

${ }^{17} \mathrm{IF} \int 23$.

${ }^{18} \mathrm{IF} \int 115$.

${ }^{19}$ Wittgenstein, L. (1987): Observaciones sobre los fundamentos de la matemática, Madrid, Alianza, IV, $\int 12$. [En lo sucesivo se citará con las siglas «OFM»].
} 
lejos, Wittgenstein ve un claro ejemplo de «buena imagen» en la imagen de la Tierra como esfera, pues se trata de una imagen simple que se acredita en cualquier situación: o lo que es lo mismo, cuando trabajamos con ella no hay lugar alguno para la duda o confusión ${ }^{20}$. Según Reguera, podremos ceder a la tentación de usar las imágenes no cuando asuman el papel de la realidad o el de una regla de uso en el lenguaje, sino cuando se tomen como meras ilustraciones que confieren plasticidad al lenguaje y por extensión a su significado ${ }^{21}$. Las palabras que se convierten en imágenes nocivas son aquellas que no tienen un significado claro y acaban confundiéndose con la realidad misma. Tal y como dijo el propio Wittgenstein, la imagen correcta ayuda; pero matiza que la imagen falsa confunde ${ }^{22}$ porque no es fácil ver sinópticamente cuál es su aplicación ${ }^{23}$. De ahí que Wittgenstein se empeñe en aclarar cuál es el uso o aplicación que se hace de las imágenes que nos encontramos en cada $\mathrm{caso}^{24}$.

Cuando se advierte o simplemente se intuye la nociva influencia de una imagen o la confusión conceptual a la que aboca un enredo de reglas lingüísticas, se padece un «problema filosófico» que se manifiesta como una toma de conciencia del desorden de nuestros conceptos, lo cual resulta irritante ${ }^{25}$ : el propio Wittgenstein manifiesta que «la falta de claridad en filosofía es una tortura. Se la siente como algo vergonzoso» ${ }^{26}$. Enfrentarse a la descripción de fenómenos difícilmente aprehensibles, la esquiva experiencia presente o cosas similares ${ }^{27}$ permite comparar esta tarea con la lucha contra algo tan agobiante como un enjambre de mosquitos $^{28}$. Cuando se padece un problema filosófico, lo único que está claro de entrada es que se lucha contra el lenguaje ${ }^{29}$, o más concretamente, contra la fas-

\footnotetext{
${ }^{20}$ SC $\int 147$.

${ }^{21}$ Reguera, I. (2002): Ludwig Wittgenstein. Un ensayo a su costa, Madrid, EDAF, p. 219.

${ }^{22}$ Wittgenstein, L. (1994a): Observaciones sobre los colores, Barcelona, Paidós, III, S 20. [En lo sucesivo se citará con las siglas «ObCol»].

${ }^{23}$ Cfr. IF $\int 422$.

${ }^{24}$ IF $\int 423-424$.

${ }^{25}$ Wittgenstein, L. (1997b): Ocasiones filosóficas 1912-1951, Madrid, Cátedra, pp. 173, 181. [En lo sucesivo se citará con las siglas «OcF»].

${ }^{26} \mathrm{ObCol}, \mathrm{III}, \int 33$.

${ }^{27}$ Cfr. IF $\int 436$.

${ }^{28}$ Wittgenstein, L. (2000a): Movimientos del pensar. Diarios 1930-1932/1936-1937, Valencia, PreTextos, \ 125.

${ }^{29}$ Wittgenstein, L. (1996): Cultura y valor. Aforismos, Madrid, Austral, \57. [En lo sucesivo se citará con las siglas «CV»].
} 
cinación que producen en nosotros las formas de expresión ${ }^{30}$. Dichos problemas tienen «el carácter de lo profundo» porque surgen de la mala interpretación de las formas lingüísticas ${ }^{31}$ : al enraizarse profundamente en el lenguaje, es como si se enraizaran también en nosotros, por lo que se manifiestan en forma de «profundas inquietudes ${ }^{32}$. No ha de extrañar, por tanto, que Wittgenstein compare el padecimiento que entraña un problema filosófico con el sufrimiento apreciable en una mosca cuando queda atrapada dentro de una botella ${ }^{33}$. De hecho, Wittgenstein señala que un problema filosófico puede ser expresado con las palabras: «No sé salir del atolladero» ${ }^{34}$. A mi modo de ver, cabe destacar dos aspectos de esta expresión. En primer lugar, aparece en primera persona del singular: pues carece de sentido decir que cierto sujeto tiene un problema filosófico aunque él mismo niegue tal cosa, así como tampoco tiene sentido alguno referirse a un problema filosófico que nunca ha sido sufrido por nadie. En segundo lugar, la expresión «No sé salir del atolladero» denota ansiedad. Perissinotto destacó que un problema filosófico es un problema que genera un tipo de ansiedad que no se puede verter en una cuestión empírico-científica ${ }^{35}$, mas no fue el único autor que se expresó en estos términos: Jacquette habló, en este mismo sentido, de «ansiedad intelectual» (intellectual anxiety) ${ }^{36}$; Genova, de «ansiedad filosófica» (philosophical anxiety) $^{37}$, y Ferrater, de «ansiedades humanas» (buman anxieties) ${ }^{38}$. Cabe suponer que fue la necesidad de aliviar esta ansiedad lo que llevó a Wittgenstein a afirmar que «el filósofo trata una pregunta como una enfermedad» ${ }^{39}$. Concretamente, se

\footnotetext{
${ }^{30}$ Wittgenstein, L. (1993): Los Cuadernos Azul y Marrón, Madrid, Tecnos, p. 56. [En lo sucesivo se citará con las siglas «CAM»].

${ }^{31}$ IF $\int 111$.

32 Ibíd.

${ }^{33}$ IF $\int 309$. El propio Wittgenstein ya precisó en su momento que a la mosca hay que enseñarle algo nuevo; algo que, si pensamos en personas, permita decir que se le ha curado de una ceguera o que se ha cambiado su geometría, como podría ser el caso si a ese sujeto se le mostrara una nueva dimensión del espacio (OFM, I, $\left.\int 44\right)$.

${ }^{34}$ IF $\int 123$.

${ }^{35}$ Perissinotto, L. (1990): «Wittgenstein on Socrates and Philosophy», en Haller, R. y Brandl, J. (eds.), Wittgenstein - Towards a Re-Evaluation. Proceedings of the $14^{\text {th }}$ International Wittgenstein Symposium (vol. II), Vienna, Hölder-Pichler-Tempsky, p. 232.

${ }^{36}$ Jacquette, D. (1998): Wittgenstein's Thought in Transition, Indiana, Purdue University Press, p. xii.

${ }^{37}$ Genova, J. (1995): Wittgenstein: $A$ W ay of Seeing, New York and London, Routledge, p. 113.

${ }^{38}$ Ferrater, J. (1978): «Wittgenstein, a Symbol of Troubled Times», en Fann, K. T. (ed.), Ludwig Wittgenstein: The Man and His Philosophy, New Jersey, Humanitites Press, 1978, p. 109.

${ }^{39}$ IF $\int 255$.
} 
trata de una enfermedad filosófica que tiene una de sus causas principales en la dieta unilateral que nos lleva a nutrir nuestro pensamiento sólo con un tipo de ejemplos ${ }^{40}$. Dicho de otro modo, acostumbramos a nutrir nuestro pensamiento con los ejemplos que tenemos más a mano, es decir, con los usos más corrientes del lenguaje. Sin embargo, esos usos corrientes no nos permiten reparar en el efecto de obstrucción y entorpecimiento que sobre nuestro entendimiento ejercen las imágenes nocivas. Ante esta tesitura, la tarea del filósofo consistirá no en ofrecer explicación alguna — por ejemplo, del origen de la confusión- sino en describir diversos usos del lenguaje: la disolución de un problema filosófico se logrará «no aduciendo nueva experiencia, sino compilando lo ya conocido» ${ }^{41}$. Por tanto, la dieta a seguir para disolver problemas filosóficos debería basarse sobre todo en ejemplos alternativos o distintos de los habituales, de modo que el sujeto afectado pueda tomar así conciencia de las imágenes dañinas. Se trata, en resumidas cuentas, de dejar de ceñirnos única y exclusivamente al punto de vista acostumbrado para pasar a contemplar nuestro uso del lenguaje desde diversas perspectivas, de manera que alcancemos una visión más amplia de los distintos usos del lenguaje. El objetivo, en palabras de Wittgenstein, consiste en cambiar nuestro «modo de ver» para que consideremos de manera diferente un caso dado ${ }^{42}$ : una vez que hayamos provisto nuestra dieta de ejemplos suficientes como para reparar en la imagen nociva, habremos dado el primer paso para que ésta deje de ejercer su influencia sobre nosotros. Wittgenstein ilustra de manera ciertamente curiosa esta estrategia cuando apunta que el método para filosofar consiste en enloquecer y en curar posteriormente esa locura ${ }^{43}$. Para entender esta extraña recomendación es preciso tener en cuenta, antes de nada, que Wittgenstein compara las cavilaciones filosóficas con las de un loco $^{44}$ porque ambos coinciden al ver problemas allí donde realmente no hay ninguno ${ }^{45}$ : y no lo hay porque este tipo de problemas no tiene cabida dentro de nuestro uso ordinario del lenguaje. Así pues, Wittgenstein pretende hacernos partícipes de la necesidad de llegar al punto en que se encuentra el sujeto desorientado por un problema filosófico —enloque-

\footnotetext{
${ }^{40} \operatorname{IF} \ 593$.

${ }^{41}$ IF $\int 109$.

${ }^{42}$ Wittgenstein, L. (1985): Zettel, México, UNAM, \461. [En lo sucesivo se citará con la sigla 《Z»].

${ }^{43}$ Wittgenstein, L. (2000b): Wittgenstein's Nachlass: The Bergen Electronic Edition. Text and Facsimile Edition, Oxford, Oxford University Press, Manuscrito 109, p. 84.

${ }^{44}$ Cfr. SC $₫ 467$.

${ }^{45}$ Wittgenstein, L. (1992): Gramática fillosófica, México, UNAM, I, $\$ 9$.
} 
ciendo con él, por así decir-, tras lo cual hay que idear algún tipo de estratagema que permita al sujeto en cuestión cobrar una perspectiva suficientemente amplia de nuestro uso del lenguaje como para liberarle del enredo conceptual en que se halla preso. Como esta estratagema o maniobra puede resultar un tanto extraña cuando se contempla en sí misma o independientemente del fin para el que fue elaborada, Wittgenstein matiza que sólo se pueden solucionar los problemas del filósofo si se piensa de forma mucho más loca que él ${ }^{46}$. Naturalmente, el hecho de que Wittgenstein presente al filósofo como «aquel que ha de curar en sí mismo muchas enfermedades del entendimiento antes de que pueda llegar a las nociones del sentido común» ${ }^{47}$ no significa que los problemas filosóficos deban ser solucionados recuperando el sentido común, ya que el filósofo no ha perdido el sentido común; por consiguiente, la tarea filosófica se reducirá a disolver las confusiones lingüísticas a las que se reducen nuestros problemas filosóficos.

\section{Terapia sistémica y juegos de lenguaje}

Tras haber presentado las líneas básicas del enfoque sistémico y de la filosofía tardía de Wittgenstein, en el presente apartado pretendo describir una serie de paralelismos entre ambos. Con ese fin, es preciso que comience mostrando cómo el concepto de «juego de lenguaje» puede ser sumamente útil no sólo para los objetivos filosóficos de Wittgenstein, sino también para el terapeuta sistémico. Así, partiendo de que el juego de lenguaje se puede contemplar como un conjunto de reglas más o menos flexible ${ }^{48}$, es evidente que lo que le interesa a Wittgenstein en relación con los juegos de lenguaje es analizar cómo se confunden las reglas de distintos juegos o identificar las imágenes que, incrustadas en nuestros juegos de lenguaje, condicionan y entorpecen nuestro entendimiento. Por consiguiente, sólo le interesan los modos en que cada cual juega un juego de lenguaje en la medida en que esas maneras de jugarlos dan lugar a un problema filosófico. Sin embargo, es evidente que hay muchas formas distintas de jugar un mismo juego de lenguaje: de qué forma se juegue dependerá de facto-

${ }^{46}$ Wittgenstein, L. (1984), Vermischte Bemerkungen (Werkausgabe, Band 8), Frankfurt am Main, Suhrkamp, p. 557.

${ }^{47}$ OFM, V, $₫ 53$.

${ }^{48}$ Por poner sólo un par de ejemplos, contrasta fuertemente la flexibilidad del juego de lenguaje poético con la rigidez del juego de lenguaje del saludo militar. 
res como la personalidad, el estado anímico y las intenciones de cada usuario del lenguaje, así como de las circunstancias puntuales en que se vea involucrado. Podemos resumir lo dicho hasta el momento señalando que el juego de lenguaje, tomado en sí mismo, no es nada más que una serie de reglas que en la gran mayoría de los casos no hemos aprendido explícitamente, sino gracias a la observación y a la práctica continuada. Ahora bien, cada vez que se es partícipe de un juego de lenguaje se lo juega de determinada manera: de forma sumisa o dominante, victimista o agresiva, inocente o manipuladora, seria o alegre, etc. No se puede jugar un juego de lenguaje de forma totalmente aséptica, así como tampoco se puede jugar un juego de lenguaje en el que participan otras personas sin influirlas de algún modo. De hecho, cuando dos o más personas juegan diversos juegos de lenguaje de forma habitual es probable que, al menos durante períodos prolongados de tiempo, quepa distinguir una pauta de juego entre ellos que se repite con frecuencia. Esta pauta puede variar repentinamente o mantenerse sin experimentar apenas alteración alguna durante décadas enteras. Además, cabe la posibilidad de que dicha pauta se mantenga sin que sus participantes reparen siquiera en ella; pero puede ocurrir también que uno, varios o incluso todos los sujetos implicados en dicha pauta la perciban como molesta o dañina.

Dicho esto, parece evidente que la noción de «juego de lenguaje» puede desempeñar un importante papel a la hora de localizar los distintos sistemas interrelacionales que se transmiten a través del lenguaje, especialmente el sistemaproblema. Precisamente porque los juegos de lenguaje son lo suficientemente flexibles como para poder ser jugados de distintas maneras, puede resultar útil analizar el estado de convivencia dentro de un grupo tomando como unidad de medida o referencia las reglas de los juegos de lenguaje jugados en el seno de ese grupo. Efectivamente, las reglas de los distintos juegos de lenguaje se pueden tomar como un armazón elemental al que hay que añadir tanto jugadores como sus formas de jugar. La interrelación entre las formas de jugar que un grupo manifieste al participar en determinado juego de lenguaje dará lugar a una dinámica única e irrepetible, pues es imposible que se repitan literalmente todas las acciones y conversaciones que tuvieron lugar durante largo tiempo en el seno de un grupo al jugar cierto juego de lenguaje. Cuando esas formas de jugar o dinámicas grupales que tienen lugar al tomar parte de determinado juego de lenguaje persisten de forma más o menos estable y reconocible nos hallamos ante un sistema interrelacional, el cual devendrá sistema-problema si su dinámica resulta dolorosa o molesta para algunos miembros del grupo. Como podemos 
apreciar, la terapia sistémica no aborda un problema que tenga su origen en un sujeto concreto, sino que se centra en algo externo al sujeto como es la forma de relacionarse que tienen dos o más personas ${ }^{49}$. De forma similar, la modalidad de terapia filosófica desarrollada y puesta en práctica por Wittgenstein está enfocada a la clarificación de una confusión conceptual que tiene lugar al usar juegos de lenguaje. Partiendo de esta similitud, llama la atención que la terapia sistémica niegue que su objeto de estudio y tratamiento sean enfermedades y que Wittgenstein, por otra parte, compare el problema filosófico con una enfermedad. Para arrojar luz sobre esta divergencia podemos recurrir al diccionario de la Real Academia Española, pues dicho diccionario contiene tres acepciones del término «enfermedad» cuyo análisis puede resultarnos de ayuda. Concretamente, el diccionario de la Real Academia Española afirma que se entiende por «enfermedad», en primer lugar, una «alteración más o menos grave de la salud»; en segundo lugar, una «pasión dañosa o alteración en lo moral o espiritual», y en tercer lugar, una «anormalidad dañosa en el funcionamiento de una institución, colectividad, etc.». Como podemos ver, las dos primeras acepciones ubican la enfermedad, de un modo u otro, en el interior del sujeto, mientras que la tercera presenta la enfermedad como un problema externo al sujeto, de manera que también el mal funcionamiento o las deficientes relaciones existentes dentro de determinado colectivo se pueden denominar «enfermedad». A resultas de lo dicho, ¿cómo conciben la enfermedad los terapeutas sistémicos y Wittgenstein? Los terapeutas sistémicos toman la enfermedad en el primer sentido, o sea, al modo clásico o como algo que cierto individuo tiene, por lo que aparece como enfermo y es susceptible de ser diagnosticado. Los terapeutas sistémicos se oponen frontalmente a esta cosificación de la enfermedad y a la consiguiente patologización del paciente: de ahí que le denominen «cliente» y que centren su atención no en una enfermedad o patología concreta sino en las pautas de relación que resultan dañinas o molestas para los miembros de determinado sistema interaccional. Wittgenstein, en cambio, entiende la enfermedad en el segundo sentido, es decir, como algo externo al sujeto. Así que acepta considerar el problema filosófico como una enfermedad porque no cree que el filósofo - y por

\footnotetext{
${ }^{49}$ Un evaluador anónimo ha advertido que en este caso hay que tomar el término «externo» con reservas, ya que hablando en rigor, el enfoque sistémico viene a diluir la distinción entre lo interno y lo externo al sujeto: pues el sujeto se define también en el contexto de las relaciones y a partir de ellas. Aprovecho para agradecer al evaluador anónimo que me haya comunicado esta interesante observación.
} 
extensión, cualquier sujeto enredado en una confusión conceptual — realmente tenga una enfermedad o haya perdido el sentido común ${ }^{50}$. A los ojos de Wittgenstein, el filósofo está sano. Su único problema es que no es capaz de distinguir cómo se ha enredado su uso del lenguaje, por lo que hay que ayudarle a aclarar su visión y a desenredar los problemas filosóficos como si de nudos se tratara: así pues, la complejidad de la tarea filosófica estará en función de la complejidad de los nudos que haya que desatar ${ }^{51}$. Por tanto, el hecho de que Wittgenstein contemple el problema filosófico como una «enfermedad» (Krankheit) no quiere decir que sea partidario ni de la cosificación de la enfermedad ni de la patologización del cliente a las que tan frontalmente se oponen los terapeutas sistémicos, sino todo lo contrario: así como en la terapia sistémica se parte de que un hecho o una serie de hechos puntuales generaron un sistema interrelacional dañino — el sistema-problema— que se consolidó por medio del lenguaje, Wittgenstein ve una imagen confusa o un mero enredo conceptual en el origen del problema filosófico.

Otra similitud entre los terapeutas sistémicos y Wittgenstein radica en su convicción de que los problemas que tratan no requieren una solución, sino una disolución. Como bien dice Ludewig, es arriesgado hablar de soluciones cuando se trata de intervenir en sistemas psíquicos y sociales: más bien se debería decir que los seres humanos reproducen problemas a través de la comunicación, por lo que también está en su mano evitar dicha reproducción y consolidación del problema. Según Ludewig, los problemas que se generan a partir de la interacción entre individuos no pueden ser solucionados o curados, sino disueltos una vez que dejen de ser reproducidos ${ }^{52}$ : así, los sistemas-problema se disuelven cuando sus miembros renuncian a seguir haciendo todo aquello que contribuía al mantenimiento del sistema-problema. Wittgenstein, por su parte, llega a afirmar que los problemas filosóficos deben ser disueltos como si de un terrón de azúcar en el agua se tratara ${ }^{53}$ : la claridad filosófica a la que aspira es «comple-

\footnotetext{
${ }^{50}$ En palabras de Wittgenstein, la tarea filosófica no exige reafirmar los puntos de vista del sentido común: «Un filósofo no es un hombre que haya perdido el sentido, una persona que no vea lo que todo el mundo ve» (CAM, p. 92).

${ }^{51}$ Z \ 452. Según Wittgenstein, la tarea del filósofo consiste en «desenredar muchos nudos». Ver Wittgenstein, L. (1994b): Últimos escritos sobre la filosofía de la psicología (vol. I), Madrid, Tecnos, S 756.

${ }^{52}$ Ludewig (2010), pp. 119-120.

${ }^{53}$ OcF, p. 181.
} 
ta», por lo que «los problemas filosóficos deben desaparecer completamentes» ${ }^{54}$. A decir verdad, no nos debe extrañar en demasía que Wittgenstein se exprese de una forma tan tajante: si a su juicio los problemas filosóficos se pueden comparar con nudos que se han producido entre distintos juegos o usos del lenguaje, una vez que se hayan desenredado todos los nudos que nos incomodan en un momento dado se habrá disuelto totalmente el problema de turno. Esta concepción de la filosofía puede parecer decepcionante a aquellas personas que a través de una abnegada labor filosófica pretendan hallar soluciones a problemas filosóficos, algunos de los cuales llevan varios milenios pendientes de recibir una solución definitiva como si de oscuros e intrigantes enigmas se tratara. Según Wittgenstein, para estas personas la solución de los problemas filosóficos es comparable a los regalos de los cuentos, que en primera instancia parecen maravillosos y a la luz del día no son más que un trozo de metal sin encanto alguno ${ }^{55}$ : al fin y al cabo, si las cuestiones metafísicas no son sino enredos conceptuales, la búsqueda de una solución científica a dichas cuestiones es una tarea abocada al fracaso.

Para llevar a cabo esta tarea de disolución de sistemas-problema y de problemas filosóficos, el terapeuta y el filósofo harán las veces de guías. Como bien dicen Boscolo y Bertrando, el terapeuta halla con frecuencia que los clientes parecen limitarse a jugar sólo determinados juegos de lenguaje y no otros, por lo que debe intentar que el cliente consiga jugar otros juegos para escapar así a esa rutina que no hace sino perpetuar su sufrimiento: además, estos autores destacan que «experimentar emotivamente (y no sólo cognitivamente) nuevos juegos lingüísticos contribuye a cambiar las premisas y la visión de la realidad» ${ }^{56}$. En resumidas cuentas, se trata de hallar el modo de desestabilizar aquellos elementos emocionales, cognitivos y por encima de todo interrelacionales que contribuyen a la estabilización del sistema-problema. Algunas de las medidas que según Ludewig se pueden adoptar para lograr este objetivo son la reflexión conjunta, la propuesta de interpretaciones y metáforas que resulten incompatibles con aquellos procesos que mantienen el problema, la prescripción de actividades que faciliten la progresiva disolución de la férrea estructura cerrada del sis-

${ }^{54} \mathrm{IF} \int 133$.

${ }^{55} \mathrm{CV} \ 58$.

${ }^{56}$ Boscolo, L. y Bertrando, P. (2008): Terapia sistémica individual, Buenos Aires, Amorrortu, p. 185.

ÉNDOXA: Series Filosóficas, n. ${ }^{2}$ 29, 2011, pp. 195-218. UNED, Madrid 
tema-problema, etc. ${ }^{57}$ Pero en principio el enfoque sistémico permite que el especialista utilice cualquier técnica terapéutica que ayude a lograr el objetivo deseado. Al igual que sucede con el método filosófico de Wittgenstein, lo importante es el objetivo a alcanzar, en tanto que la amplia batería de medios que se pueden utilizar para ello parece quedar en un segundo plano debido a su heterogeneidad, o mejor dicho aún, a la necesidad de adaptar cuidadosamente esos medios a las características particulares del problema y de la persona o personas que lo padecen $^{58}$. Así, entre los recursos utilizados por Wittgenstein para disolver problemas filosóficos se hallan el planteamiento de casos imaginarios, metáforas, preguntas retóricas, usos diversos del lenguaje, etc. Al ayudar al filósofo a pasar de su confusión conceptual a una visión sinóptica del uso del lenguaje, Wittgenstein le permite ver dónde radicaba el problema filosófico de turno, lo cual facilita su disolución ${ }^{59}$. Como tuvimos oportunidad de comprobar, Wittgenstein pretende cambiar nuestro «modo de ver» (Anschaunngsweise) para que consideremos de manera diferente un caso dado ${ }^{60}$. De manera similar, en el ámbito sistémico hay que ayudar al cliente a afrontar la situación problemática desde un marco de referencia más amplio: en palabras de Efran, Lukens y Lukens, «para ser útil, un terapeuta debe poseer la capacidad de trascender el marco del lenguaje en el cual está atrapado el cliente» induciéndole a abandonar el marco inicial que abocaba al cliente a contemplar sus problemas de una única manera y, por tanto, a imaginar siempre las mismas soluciones ${ }^{61}$. En el caso de Wittgenstein, pro-

${ }^{57}$ Ludewig (2010), p. 119.

${ }^{58}$ En relación con este particular, Wittgenstein escribió lo siguiente: «[S]e muestra ahora un método con ejemplos», tras lo cual se lee «No hay un único método en filosofía, si bien hay realmente métodos, como diferentes terapias» (IF $\ 133$ ). Hilmy se apercibió de la aparente inconsistencia que radica en mantener, por un lado, que va a mostrar un método, y por otro, que en realidad no existe un método sino muchos. Ante esta aparente incongruencia, la interpretación que ofrece Hilmy al conectar ambos fragmentos parece obvia: al hablar de «método» en singular, Wittgenstein se estaría refiriendo al procedimiento general dirigido a disolver los problemas filosóficos, mientras que al hablar en plural estaría haciendo mención a las diversas formas de disolver cada problema. Ver Hilmy, S. S. (1987): The Later Wittgenstein, Oxford, Blackwell, pp. 3-4, 227.

${ }^{59}$ En palabras de Wittgenstein: «Este enredarse en nuestras reglas es lo que queremos entender, es decir, ver sinópticamente» (IF \ 125).

${ }^{60}$ Ver nota 43.

${ }^{61}$ Efran, J. S., Lukens, M. D. \& Lukens, R. J. (1994): Lenguaje, estructura y cambio. La estructuración del sentido en psicoterapia, Barcelona, Gedisa, p. 189. En esta misma línea, Maturana y Varela llaman la atención sobre la necesidad de variar la naturaleza de la cuestión que embarga al cliente de modo que la nueva cuestión planteada permita abarcar un contexto más amplio. Cfr. Maturana, H. R. y Varela, F. J. (1987): The Tree of Knowledge: The Biological Roots of Human Understanding, Boston, Shambhala, p. 135. 
porcionar al filósofo una rica y variada dieta de ejemplos debería ayudarle a salir de su estancamiento conceptual. Pero así como el nutricionista no sólo debe conocer con detalle el caso de su cliente sino que además ha de formarse una imagen de dicho caso que le permita decidir qué dieta es la más adecuada, Wittgenstein advierte que en filosofía hay que preguntarse siempre cómo se debe enfocar cada problema para que se torne resoluble ${ }^{62}$. Esta necesidad de enfocar adecuadamente el problema a tratar y de elaborar una estrategia para disolverlo basta por sí misma para revelar que la tarea filosófica dista mucho de ser tan simple como el mero acto de desatar un nudo.

Por si fuera poco, en último término será algo tan subjetivo como la opinión del sujeto afectado por el problema abordado lo que dictamine el grado de éxito que han tenido la terapia sistémica o el tratamiento filosófico de determinada confusión lingüística. En el primer caso debe ser el propio cliente el que señale en qué medida se ha conseguido tanto desestabilizar el sistema-problema como activar un sistema alternativo en que los distintos miembros del grupo puedan interaccionar sin caer en las disruptivas prácticas interactivas de antaño, mientras que en el segundo caso será el sujeto previamente afectado por un problema filosófico el que precise si los recursos con los que se ha intentado disolver su problema han sido adecuados en su caso concreto, pues los recursos — metáforas, preguntas retóricas, etc.- que resulten útiles para disolver un problema filosófico a los ojos de determinada persona no tienen por qué ser necesariamente adecuados para que el problema en cuestión se disuelva a los ojos de cualquier otra persona. Si Wittgenstein ofrece —entre las entradas 243 y 315 de las Investigaciones filosóficas - una gran cantidad de recursos dirigidos a disolver la imagen de un objeto privado que a su vez constituyera la referencia de un supuesto lenguaje privado no es sólo por la importancia de afrontar este crucial problema filosófico desde múltiples perspectivas, sino también para trabajar sobre uno mismo y las propias resistencias. De hecho, es ésta la principal dificultad a la que deben hacer frente la terapia sistémica y la wittgensteiniana: la de afrontar las resistencias que surgirán a medida que se aproxime la disolución del problema de turno. Efectivamente, cuando un grupo decide recurrir a la terapia sistémica es frecuente que lleve ya mucho tiempo envuelto en un sistema-problema, por lo que su disolución conllevaría también serias dificultades para esas mis-

${ }^{62}$ ObCol, II, \} 1 1 . 
mas personas que están intentando liberarse del mismo. Sin ir más lejos, a los clientes les resultará difícil hacerse a la idea de que pueden relacionarse de otra manera, y tanto o más difícil aún les resultará adaptarse a esa nueva forma de interaccionar. Al fin y al cabo, dicho cambio puede conllevar retos como hacer frente al propio orgullo; renunciar a una posición mantenida — a veces con suma testarudez - durante mucho tiempo para adoptar en su lugar otra que puede aumentar sobremanera la sensación de vulnerabilidad; afrontar el temor a una forma de relacionarse que puede resultar desconocida y sobre la cual tal vez no se tenga claro si resultará igualmente problemática, etc. Ante esta tesitura, el terapeuta debe generar un clima de confianza y basarse en el diálogo para estimular sutilmente a sus clientes a llevar a cabo ese cambio deseado al que hasta entonces venían resistiéndose. En lo que respecta al método filosófico de Wittgenstein, las resistencias tendrán que ver no sólo con la dificultad de contentarnos con una mera descripción sin pretender ir más allá en busca de una explicación ${ }^{63}$, sino también, y sobre todo, con la diferencia existente entre la asimilación de lo visto y lo que la mayoría de los hombres quiere ver. Según el filósofo vienés, «lo que hay que vencer no es una dificultad del entendimiento sino de la voluntad $\diamond^{64}$, por lo que «el trabajo filosófico (...) consiste, fundamentalmente, en trabajar sobre uno mismo. En la propia comprensión. En la manera de ver las cosas. (Y en lo que uno exige de ellas) ${ }^{65}$.

\section{A modo de conclusión}

En este apartado final quiero aclarar qué se aportan mutuamente la teoría sistémica y la filosofía tardía de Wittgenstein en relación con la disolución de los sistemas-problema y los problemas filosóficos. En cuanto a los sistemas-problema podemos decir que su disolución entraña comenzar a jugar no sólo juegos nuevos sino también los juegos habituales, si bien de una manera distinta a la acostumbrada. Una vez que se ha adquirido una perspectiva más amplia de la rigidez con que se jugaba determinado juego, y si además se ha comenzado a experimentar el alivio emocional y cognitivo que entraña participar en juegos alternativos, será más sencillo para el cliente liberarse de la tiranía del sistema-

\footnotetext{
${ }^{63}$ Cfr. Z $₫ 314 ;$ OFM, VI, \ 31.

${ }^{64} \mathrm{CV} \ 91$.

${ }^{65} \mathrm{CV} \ 84$.
} 
problema como imagen —entendida en el sentido wittgensteiniano- desde la que se juzga a uno mismo y a los demás. Así pues, el sistema-problema se disuelve a medida que deja de ser jugado, si bien hay que tener presente que dicho sistema puede reaparecer a lo largo de ese proceso de disolución si se dan determinadas circunstancias que coadyuven a su reactivación.

Pasando ya a la disolución de los problemas filosóficos, llama la atención que Wittgenstein afirme rotundamente que la filosofía «[d]eja todo como está» ${ }^{66}$. En este caso puede llevar a confusión que Wittgenstein use el término «todo» para referirse única y exclusivamente al uso efectivo del lenguaje. Es cierto que si la filosofía se reduce a deshacer enredos conceptuales, las reglas del lenguaje no experimentarán variación alguna ${ }^{67}$. Pero las reglas y el uso del lenguaje no son «todo». ¿Pues qué hay del sujeto que se ha liberado del problema filosófico? ¿Acaso seguirá siendo todo igual para él? En mi opinión, la respuesta es negativa. Aunque las reglas lingüísticas permanezcan intactas, la experiencia que ha tenido el sujeto al afrontar su problema filosófico le habrá mostrado qué imagen le sedujo, cómo mezcló reglas de juegos de lenguaje distintos, etc. Por tanto, habrá aprendido cómo evitar caer de nuevo en el mismo problema. En relación con el enfoque sistémico, dice Ludewig, cuando el proceso terapéutico finaliza con la disolución del sistema-problema «sus miembros regresan a su vida cotidiana, pero ahora liberados de la carga de tener que reproducir el problema» ${ }^{68}$. En una línea similar, Hodges y Lachs mantienen que las tareas filosóficas que propone Wittgenstein no consisten en ofrecer o atacar tesis, sino en evitar tentaciones ${ }^{69}$. Y en este caso se trata de evitar la tentación tanto de ser seducido de nuevo por la imagen nociva como de incurrir en la confusión de reglas, mientras que aquellos sujetos que han disfrutado de los beneficios de la terapia sistémica saben qué tentaciones han de evitar — como abrir viejas heridas o volver a entrar en antiguas pautas dañinas de relación - para que no resurjan los problemas que les llevaron a solicitar los servicios del terapeuta. En resumidas cuentas, ni la terapia sistémica ni la filosofía wittgensteiniana tienen nada que ver con

${ }^{66}$ IF \ 124. Según el propio Wittgenstein, lo que se destruye son castillos en el aire, con lo que dejamos libre la base del lenguaje sobre la cual se asientan (IF $\int 118$ ).

${ }^{67}$ Cfr. IF $\int 133$.

${ }^{68}$ Ludewig (2010), p. 91.

${ }^{69}$ Hodges, M. P. \& Lachs, J. (2000): Thinking in the Ruins. Wittgenstein and Santayana on Contingency, Nashville, Vanderbilt University Press, p. 106. 
métodos quirúrgicos que permiten extirpar limpiamente y de una vez por todas determinado problema sin exigir otra cosa del sujeto que lo padece aparte de una actitud total y absolutamente pasiva: lejos de tal cosa, la terapia sistémica y la filosofía wittgensteiniana proporcionan orientaciones y estrategias para que cada sujeto, en el seno de los sistemas de los que forma parte o en la soledad de sus cavilaciones filosóficas, tenga más recursos con los que enfrentarse a sí mismo y a las tentaciones que ya le llevaron muchas veces por sendas y caminos a los que, en principio, no quiere retornar. Así pues, afirmar que la filosofía deja absolutamente todo tal y como está sería como decir que la terapia sistémica al igual que la propia filosofía-, aunque no provoque una transformación de las reglas de nuestros juegos de lenguaje ordinarios, no puede alterar la forma de jugarlos ni tener efecto liberador alguno sobre las personas que acuden a ella.

\section{Bibliografía}

Anderson, H. \& Goolishian, H. (1988). «Human systems as linguistic systems: evolving ideas for the implications in theory and practice», Family Process, XXVII, pp. 371393.

- (1992). «The client is the expert: a not-knowing approach to therapy», en McNamee, S. \& Gergen, K. J. (eds.), Therapy as Social Construction, London, Sage, pp. 25-39.

Anderson, H., Goolishian, H. \& Winderman, L. (1986). «Problem determined systems: towards transformation in family therapy», Journal of Strategic and Systemic Therapies, V, pp. 1-14.

BERMúdez, C. y BRIK, E. (2010). Terapia familiar sistémica. Aspectos teóricos y aplicación práctica, Madrid, Síntesis.

Boscolo, L., Bertrando, P., Fiocco, P. M., Palvarini, R. M. y Pereira, J. (1991). «Linguaggio e cambiamento. L'uso di parole chiave in terapia», Terapia Familiare, XXXVII, pp. 41-53.

Boscolo, L. y Bertrando, P. (2008). Terapia sistémica individual, Buenos Aires, Amorrortu.

Ceberio, M. R. y Linares, J. L. (2005). Ser y hacer en terapia sistémica. La construcción del estilo terapéutico, Barcelona, Paidós.

De Shazer, S. (1985). Keys to Solution in Brief Therapy, New York, Norton.

- (1988). Clues. Investigating Solutions in Brief Therapy, New York, Norton. 
— (1991). Putting Differences to Work, New York, Norton.

- (1994). Words Were Originally Magic, New York, Norton.

EFrAn, J. S., LukENs, M. D. \& LuKENs, R. J. (1994). Lenguaje, estructura y cambio. La estructuración del sentido en psicoterapia, Barcelona, Gedisa.

Ferrater, J. (1978). «Wittgenstein, a Symbol of Troubled Times», en Fann, K. T. (ed.), Ludwig Wittgenstein: The Man and His Philosophy, New Jersey, Humanitites Press, pp. 107-115.

Genova, J. (1995). Wittgenstein: A Way of Seeing, New York and London, Routledge.

HiLmy, S. S. (1987). The Later Wittgenstein, Oxford, Blackwell.

Hodges, M. P. \& LaCHS, J. (2000). Thinking in the Ruins. Wittgenstein and Santayana on Contingency, Nashville, Vanderbilt University Press.

JacQueTte, D. (1998). Wittgenstein's Thought in Transition, Indiana, Purdue University Press.

Ludewig, K. (2010). Bases teóricas de la terapia sistémica, México, Herder.

Maturana, H. R. y Varela, F. J. (1987). The Tree of Knowledge: The Biological Roots of Human Understanding, Boston, Shambhala.

Perissinotto, L. (1990). «Wittgenstein on Socrates and Philosophy», en Haller, R. y Brandl, J. (eds.), Wittgenstein - Towards a Re-Evaluation. Proceedings of the $14^{\text {th }}$ International Wittgenstein Symposium (vol. II), Vienna, Hölder-Pichler-Tempsky.

Reguera, I. (2002). Ludwig Wittgenstein. Un ensayo a su costa, Madrid, EDAF.

VON Bertalanffy, L. (1954). General systems theory, New York, George Brazillier.

VON SCHLIPPE, A. \& SCHWEITZER, J. (2003). Manual de terapia y asesorías sistémicas, Barcelona, Herder.

Watzlawick, P., Beavin, J. \& Jackson, D. (1967). Pragmatics of human communication, New York, Norton.

White, M. \& Epston, D. (1989): Literate Means to Theraeutic Ends, Adelaida, Dulwich Centre Publications.

WiENER, N. (1948). Cybernetics, New York, Wiley.

WitTgensteIn, L. (1984). Vermischte Bemerkungen (Werkausgabe, Band 8), Frankfurt am Main, Suhrkamp.

- (1985). Zettel, México, UNAM. [Citado con la sigla «Z»].

- (1987). Observaciones sobre los fundamentos de la matemática, Madrid, Alianza. [Citado con las siglas «OFM»]. 
— (1988). Investigaciones filosóficas, Barcelona, Crítica. [Citado con las siglas «IF»].

- (1992). Gramática filosófica, México, UNAM.

- (1993). Los Cuadernos Azuly Marrón, Madrid, Tecnos. [Citado con las siglas «CAM»].

— (1994a). Observaciones sobre los colores, Barcelona, Paidós. [Citado con las siglas «ObCol»].

- (1994b). Últimos escritos sobre la filosofía de la psicología (vol. I), Madrid, Tecnos.

- (1996). Cultura y valor. Aforismos, Madrid, Austral. [Citado con las siglas «CV»].

- (1997a). Sobre la certeza, Barcelona, Gedisa. [Citado con las siglas «SC»].

- (1997b). Ocasiones filosóficas 1912-1951, Madrid, Cátedra. [Citado con las siglas «OcF»].

- (2000a). Movimientos del pensar. Diarios 1930-1932/1936-1937, Valencia, Pre-Textos.

- (2000b). Wittgenstein's Nachlass: The Bergen Electronic Edition. Text and Facsimile Edition, Oxford, Oxford University Press.

Recibido: 5/01/2012

Aceptado: 7/03/2012 
08 27/06/12 7:22 Página 218 